\title{
OFiciNAL CONTREUTION
}

\section{A Case-control Study of Buerger's Disease}

\author{
Hiroto Nakadaira', Kazuo Endoh', Masaharu Yamamoto', Kiyomi Sakata², \\ Toshitaka Omuras, Akinori Hisashige', Masayo Kobayashi', Yutaka Kurosawa', \\ Kazuo Motegi', Masao Nakallma', Yusuke Terao', Takayuki Nose ${ }^{10}$, \\ Hirotoshi Iwata ${ }^{11}$, Ken-ichl Nakamura ${ }^{12}$, Tsutomu Hashimoto ${ }^{19}$, and Hiroshi Yanagawa ${ }^{2}$
}

\begin{abstract}
A netion-wide case-control study was conducted to identify the risk factors and to give clues to the eticlory of Buerger's disease. Cases were 153 male patients who were the receivers of national flnancilel alds for the treatment of the disease and were'enrolled in public health center. For each casa, a control was randomly belected from the list of the examinees of health examinations in the public health center aame as the case and wes matched to the cease by ace ( $\pm \mathbf{5}$ yecrs old) and sex. Seff-edministered questionneirea were malled to all shudy participants. The results of statlatical anabyes under the condition that the estimated oneet ace of the case was under 50 years old were es follows; (1) strong link between tobacco and Btwerger's dieases was statiatically reconfimed (2) cases consumed a less anount of milk then controls. (3) cases were enceaced in phyaical works more frequently and under noisier and chestler emilronments than contrats. (4) the past history of allargic ihlnitis was found more on the side of coses. I Epidemior, 1991; 1 : 19-26.
\end{abstract}

Buenger's disease, risk factors, epidemiology, a case-control study

Buerger's disease is pathologically defined as a nonatherosclerotic, segmental, inflammatory, and occlusive disease of small and medium-sized arteries and veins involving distal vessels of the upper and lower extremities. ${ }^{1-51}$ The etiology of this disease still remains obscure, whereas numerous risk factors have been postulated. ${ }^{2-9)}$ Although recently it has been suggested that Buerger's disease is an autoimmune disorder triggered by smoking, ${ }^{2 a}$ its low incidence rate makes it difficult to verify this theory.

A case-control observation is considered to be a method of utility for the study of a disease with low incidence rate. The present study thus employed a nation-wide case-control study in order to identify the risk factors and to give clues to the etiology of Buerger' s disease, collecting cases through the registry in which the patients of Buerger's disease, which is one of the intractable diseases designated by the Ministry of Health and Welfare (MHW), are to enroll to receive the national financial aids for the trearment from the MHW.

\section{waterials aNd METhODS}

Cases were 159 patients ( 153 males and 6 females) in 16 prefectures (Table 1) who were registered to receive the financial aids for the treatment of Buerger's disease between April 1988 and November 1990 and who complied with our study request.

For each case, a control was recruited, matched to

Recieved Beptember 19, 1991 ; accepted October 2, 1991.

'Department of Hygiene and Preventive Medicine. Niigata University School of Medicine, Niigata, Japan. "Department of Public Health, Jichi Medical Schoo:, Tochigi, Japan. 'Department of Public Health. Akita University School of Medicine. Akita. Japan. "Department of Public Health Care Informatics Suzuka Universily of Nedical Science and Technology. Mie, Japan. "Gano Public Heahlh Center, Tochigi, Japan. "Department at Health and Welfare, Toyama, Japan. Takahagi Public Health Center, beraki, Japan. "Department of Health and Emironmental Protection, Kyoto, Jepan. 'Department of Health and Envifonmental Protection, Osaka, Japan. ${ }^{10}$ Department of Public Health. Tottori University School of Medicine, Tottori, Japan. "Department of Hygiene, Gilu University School of Medicine. Gifu, Japan. "Department of Hygiene, Showa University School of Medicine, Tokyo, Japan. I3Department af Public Health, Wakayama Medical College, Wakayama, Japan.

Address for correspondence: Hiroto Nakadaire, Department of Hyglene and Preventive Medlcine, Nibata University School of Medicine, 757-1 Asahimachi-dori Nigata 951, Japan. 
the case by age ( \pm 5 years old) and sex. from the lists of the examinees of health examinations conducted by the sume public health centers with the case. The women who came to pregnancy check-ups and the mothers of babies and infants who visited pediatric examinations were excluded because they might make the bias of study population.

A self-administered quetionnaire was mailed to each study participants. The form contained about 40 questions. which were concerning (1) sex. (2) year and date of birth. (3) height and weight, (4) smoking habits. (5) alcohol consumption. (6) milk intake. (5) employment status. (9) medical history, (9) family history. hearing and (1) parity. Two types of quetionnaire were prepared for the case and the control, respectively. One for the case was written in the past tense to inquire the life before Buerger's disease had developed. The other for the control was in the present tense to survey the present life.

Although the questionnaire was. in principal, a self-completing one, other family members were permitted to answer the questions on behalf of the patient. Health center officers who interviewed patients were also permitted to fill in the forms, when the patients could not write by themselves because of physical handicaps.

Stalistical analyses were limited to male case-control pairs due to the small number of female data and were performed under the following three conditions. First, all the pairs in this study (this condition is called "total pairs" in this report) were analysed, and then the pairs whose cases had been under 50 years old at the onset of the disease (" age"). Finally, the data of the pairs whose cases were under 50 years old at the onset and underwent angiography for the final diagnosis f"the pairs conditioned with angiography") were fed into computer. The odds ratio (OR) of paired sample was calculated by means of McNemar's method. To explore the doseresponse relationship between smoking and Buerger's disease, the Mantel-extension analysis was performed.

\section{REESULTS}

The number of pairs in each prefecture was shown in Table I. The distributions of the present age of cases and controls and the onset age of cases were as indicated in Table 2. The means and the standard deviations of present age were $47.1 \pm 11.43$ years old and $47.3 \pm$ 11.46 years old for cases and controls, respectively. There was no significant difference in age distribution nor in the mean of present age between the case and the control. Angiographic examination was performed in $124(81.0 \%)$ out of 153 cases in total pairs and 93
Table 1. Numbers of cuse-control pairs in prefectures.

\begin{tabular}{lrrr}
\hline \multicolumn{1}{c}{ Prefeture } & Male & Female & Total \\
\hline Aomori & 11 & & 11 \\
Akita & 21 & & 21 \\
Ibaraki & 6 & 1 & 7 \\
Tochigi & 15 & 1 & 16 \\
Saitama & 3 & & 3 \\
Tokyo & 2 & & 2 \\
Niigata & 32 & & 32 \\
Toyama & 13 & & 13 \\
Ishikawa & 1 & & 1 \\
Gifu & 13 & & 13 \\
Osaka & 1 & 1 & 2 \\
Wakayana & 22 & 3 & 25 \\
Tortori & 3 & & 3 \\
Okayama & 1 & & 1 \\
Kochi & 7 & & 2 \\
Fukuoku & 2 & & 159 \\
\hline \multicolumn{1}{c}{ Total } & 153 & 6 & \\
\hline
\end{tabular}

Table 2 Age disiributions of cases and controls.

\begin{tabular}{|c|c|c|c|}
\hline \multirow{2}{*}{ Age } & \multicolumn{2}{|r|}{ Case } & \multirow{2}{*}{$\frac{\text { Control }}{\text { Present age }}$} \\
\hline & Present age & Estimuted onset age & \\
\hline $10 \sim 19$ & I 10.7 J & $2(1.4)$ & $1(0.7)$ \\
\hline $20 \sim 29$ & 1016.51 & $31(\mid 4.7)$ & $7(4,6)$ \\
\hline $30-39$ & $25(16.3)$ & $31(21.7)$ & $35(22.9)$ \\
\hline $40-49$ & 51 ( 33.3) & $55(38.4)$ & $40(26.1)$ \\
\hline $50-59$ & $45(29.4)$ & $23(16.1)$ & $49(32.0)$ \\
\hline $60-69$ & $18(11.8)$ & $9(6.3)$ & $19(12.4)$ \\
\hline $70-79$ & 312.01 & $2(1.4)$ & $2(1.3)$ \\
\hline To1al & $153(100.0)$ & $143(100.0)$ & $153(100.0)$ \\
\hline
\end{tabular}

Note: Present age was as of March 31, 1989, March 31. 1990. and November 30. 1990 for cases and controls enrolled in the year of 1988, 1989 and 1990, respectively. Onset age was escimaled by referring to medical records. Ten cases were exciuded from scoring, since their onset ages were not recorded. Figures in parentheses show percentages.

(86. $1 \%$ ) of 108 cases in the pairs conditioned with onset age.

OR and 954 confidence interval (CI) of exposure factors were presented in Tables 3,4 and 5.

of 152 cases, except one with no reply, in total pairs, 150 (98.7\%) cases answered that they had or had had smoking habits. So did 107 (99.1\%) out of 108 cases in the pairs conditioned with onset age and 91 (97.8\%) out of 93 cases in the pairs conditioned with angiography. There were commonly two nonsmokers among the pairs under each condition.

Continuous smoking habits were siginificantly associated with an increasing risk of Buerger's disease, compared with nonsmoking and cessation of smoking before the onset of Buerger's disease. Because there 
Buerger's Disease

Talye 3. Odds ratio of exposure factors. (Total Pairs)

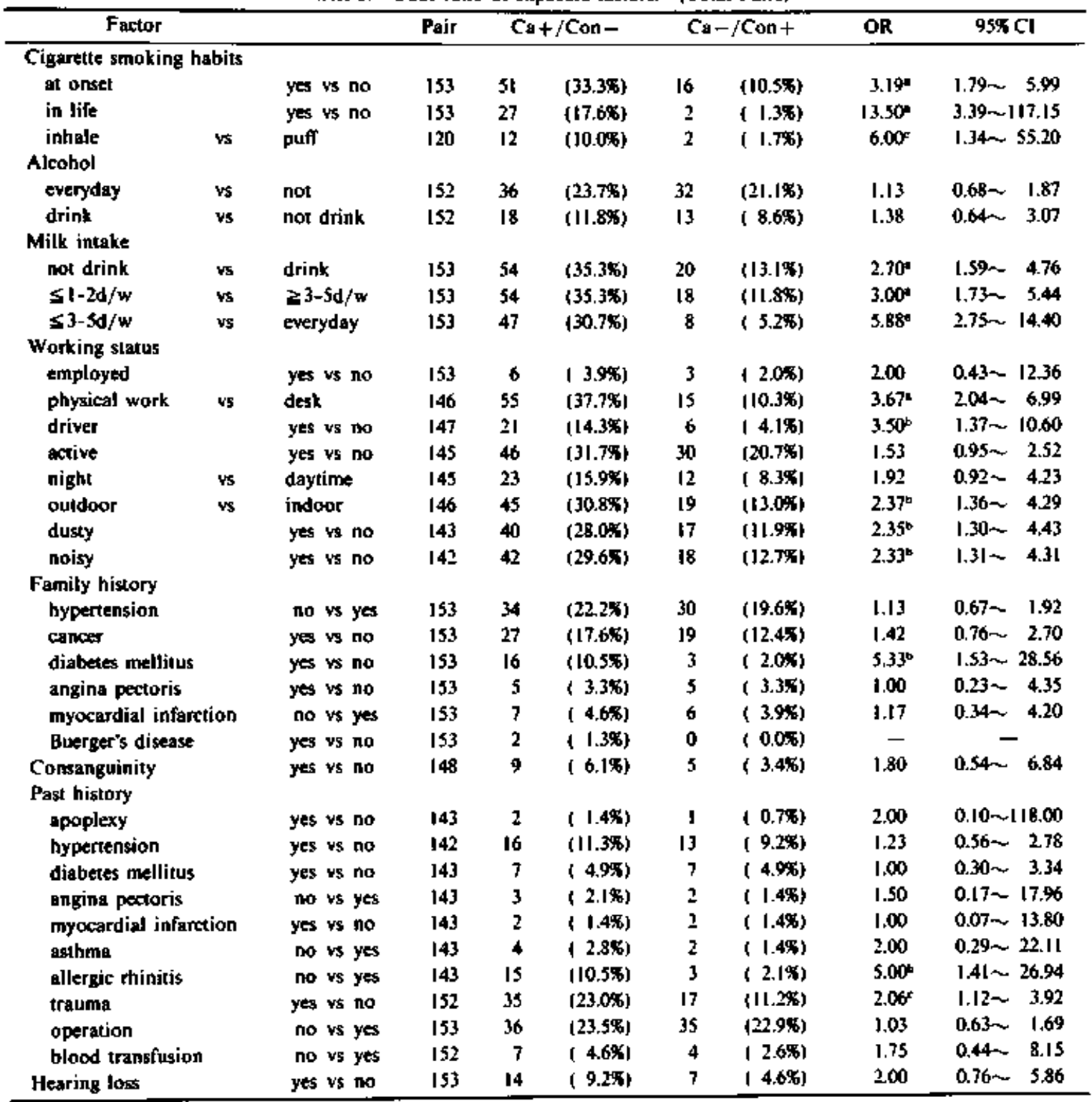

Note)significance: "p<0.001, " $p<0.01$, " $p<0.05$

Ca: caser Con : control

OR: odds ratio, CI : confidence interval

was a suspicion that those who answered that they had stopped smoking before the onset of the disease actually gave up smoking after the diagnosis, however, nonsmokers were then compared with the total of ex-smokers and current smokers. OR then increused. There was also a strong dose-response relationship between Buerger's disease and Brinkman index (Tables 6. 7 and 8 ).

Alcohol consumption had no association with Buer- ger's disease.

Less intake of milk was found to be statistically associated with Buerger's disease as shown in Tables 3. 4 and 5 .

OR of physical work for Buerger's disease was significantly higher than that of desk work. Noisy and dusty working environment were also statistically signi licant risk factors.

Family history of diabetes mellitus (DM) was stat- 
Talle 4. Odds ratio of exposure factors. (Estimated ansel age under 50 years old)

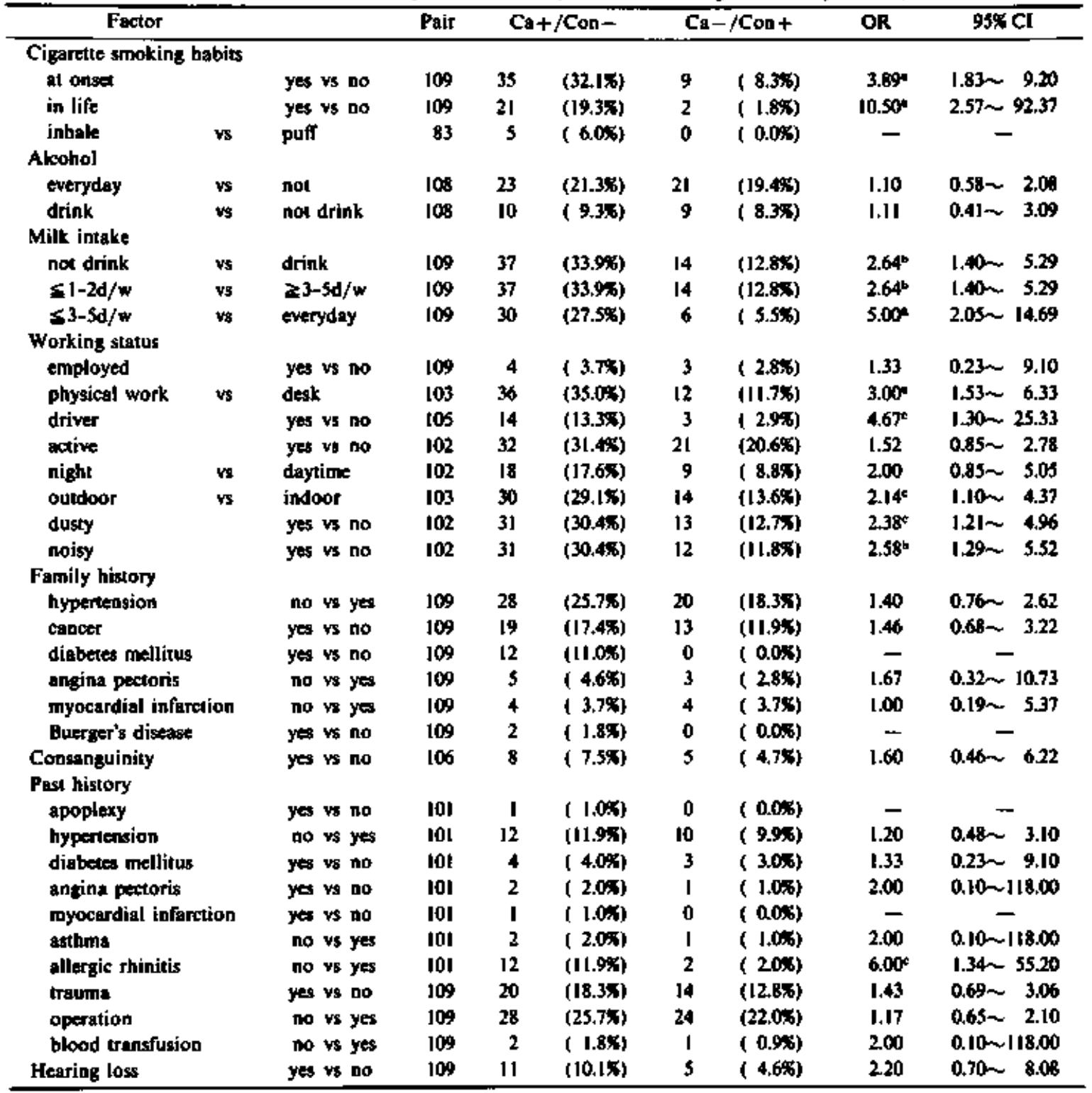

Note) significence: $" \mathrm{p}<0.001 .{ }^{b} \mathrm{p}<0.01,{ }^{\mathrm{c} p}<0.05$

Ca: case. Con ; control

OR : odds ratio, CI : confidence interval

istically associated with Buerger's disease only in total pairs. Among the pairs conditioned with onset age and the pairs conditioned with angiography, there was no case with the family history of DM.

The past history of allergic rhinitis significantly increased the risk of Buerger's disease. 
Tables Odds ratio of exposure factors. (Estimated onset age under 50 years old a snaiography performed)

\begin{tabular}{|c|c|c|c|c|c|c|c|c|c|}
\hline \multicolumn{2}{|l|}{ Factor } & & Pair & \multicolumn{2}{|c|}{$\mathrm{C}+/ \mathrm{Con}-$} & \multicolumn{2}{|c|}{$\mathrm{C}=/ \mathrm{Con}+$} & \multirow[t]{2}{*}{ OR } & \multirow[t]{2}{*}{$95 \% \mathrm{CI}$} \\
\hline \multicolumn{8}{|c|}{ Cignreate smoking habits } & & \\
\hline at poset & & yes vis no & 93 & 30 & $(32.3 \%)$ & 8 & $(8.6 \%)$ & $3.75^{\circ}$ & $1.68-9.47$ \\
\hline in life & & yes vs no & 93 & 16 & $(17.2 \%)$ & 2 & $(2.3 \times)$ & $8.00^{b}$ & $1.88-71.72$ \\
\hline inhale & vs & puff & 73 & 4 & $(5.5 \%)$ & $\mathbf{0}$ & $(0.0 x)$ & - & - \\
\hline \multicolumn{10}{|l|}{ Alcohol } \\
\hline everyday & vs & not & 93 & 21 & $(22.6 x)$ & 19 & (20.4\%) & 1.11 & $0.57=2.17$ \\
\hline drink & vs & not drink & 93 & 17 & $(18.3 \%)$ & 15 & $(16,1 \%)$ & 1,13 & $0.53 \sim 2.44$ \\
\hline \multicolumn{10}{|l|}{ Mitk intate } \\
\hline not drink & vs & drink & 93 & 30 & $(32.3 \%)$ & II & $(11.8 \%)$ & $2.73^{6}$ & $1.33 \sim 6.03$ \\
\hline $5 J-2 d / w$ & vs & $\geq 3-5 d / w$ & 93 & $\mathbf{2 9}$ & $(31.2 \%)$ & 10 & $(10.8 \%)$ & $2,90^{\circ}$ & $1.37 \sim 6.67$ \\
\hline$\leq 3-5 d / w$ & vs & everyday & 93 & 25 & $(26,9 \%)$ & 5 & $(5.4 \%)$ & 5.00 & $1.88 \sim 16.72$ \\
\hline \multicolumn{10}{|l|}{ Working status } \\
\hline employed & & yes v8 nD & 93 & 4 & $(4.3 \%)$ & $\mathbf{I}$ & $(1.15)$ & 4.00 & $0.40-196.99$ \\
\hline physical work & vs & desk & 88 & 29 & $(33.0 \%)$ & II & $(12,5 \%)$ & 2.64 & $1.28 \sim 5.85$ \\
\hline driver & & yes ys no & 91 & II & (12.1\%) & 3 & (3.3\%) & 3.67 & $0.97 \sim 20.47$ \\
\hline active & & yes us no & 88 & 27 & (30.7\%) & 20 & (22.75) & 1.35 & $0.73 \sim 2.54$ \\
\hline night & vs & daytime & 88 & 15 & $(17.0 \%)$ & 8 & $(9.1 \%)$ & 1.88 & $0.75 \sim 5.11$ \\
\hline outdoor & vs & indoer & 88 & 24 & $(27.3 \%)$ & 12 & (13.6\%) & 2,00 & $0.96 \sim 4.39$ \\
\hline dusty & & yes vs no & 87 & 26 & $(29.9 \%)$ & II & $(12,6 \%)$ & $2.36 \mathrm{c}$ & $1.13-5.30$ \\
\hline noisy & yes & is no & 87 & 26 & $(29.9 \%)$ & 10 & (11.5\%) & $2.60^{\circ}$ & $1.21 \sim 6.04$ \\
\hline \multicolumn{10}{|l|}{ Family history } \\
\hline hypertension & & no vs yes & 93 & 23 & $(24.7 \%)$ & 16 & $(17.26)$ & 1.44 & $0.73 \sim 2.91$ \\
\hline cancer & & yes is no & 93 & 16 & $(17,2 \%)$ & 12 & $(12.9 \%)$ & 1.33 & $0.59 \sim \quad 3.09$ \\
\hline diabetes mellitus & & yes vs no & 93 & [1] & (11.8\%) & 0 & $(0.0 \%)$ & - & - \\
\hline angina pectoris & & no vs yes & 93 & 3 & $(3.25)$ & 2 & $(2.2 \%)$ & 1.50 & $0.17 \sim 17.96$ \\
\hline myocardial infarctio & & yes us no & 93 & 4 & ( 4.3\%) & 3 & $(3.25)$ & 1.33 & $0.23 \sim 9.10$ \\
\hline Butger's dipesse & & yes vs no & 93 & 2 & $(2.2 \%)$ & 0 & $(0.0 \%)$ & - & - \\
\hline Consangrinity & & yes vs no & 91 & 7 & ( $7.7 \%)$ & 4 & ( 4.48) & 1.75 & $0.44 \sim 8.15$ \\
\hline \multicolumn{10}{|l|}{ Past history } \\
\hline apoplexy & & yes vs no & 85 & 1 & $(1.25)$ & 0 & $(0.05)$ & - & - \\
\hline hypartension & & no vs yes & 85 & 10 & $(11.8 \%)$ & 9 & $(10.6 \%)$ & 1.11 & $0.41 \sim 3.09$ \\
\hline diabetes mellitus & & yes vs no & 85 & 4 & ( $4.7 \%)$ & 2 & ( 245) & 2.00 & $0 . x-22.11$ \\
\hline angina pectoris & & yes is no & 85 & 2 & $(2.4 \%)$ & $\mathbf{I}$ & $(1.25)$ & 2.00 & $0.10 \sim 118.00$ \\
\hline myocerdial infarctio & & yes vo no & 85 & 1 & $(1.2 \%)$ & 0 & $(0.005)$ & - & - \\
\hline asthma & & no vs yes & 85 & 2 & $(2,4 \%)$ & $\mathbf{I}$ & $(1.25)$ & 2.00 & $0.10 \sim 118.00$ \\
\hline allergic hinitis & & no v8 yes & 85 & [1] & (12.9\%) & $\mathbf{I}$ & $(1.2 \%)$ & $11.00^{\mathrm{b}}$ & $1.60-473.47$ \\
\hline trauma & & yes vs no & 93 & 20 & $(21.5 \%)$ & I] & (11.85) & 1.82 & $0.83 \sim 4.20$ \\
\hline operation & & yes vs no & 93 & 22 & $(23.75)$ & 21 & $(22.6 \%)$ & 1.05 & $0.55=200$ \\
\hline blood transfusion & & yes us no & 93 & 2 & $(2.2 \%)$ & 0 & $(0,0 \%)$ & - & - \\
\hline Hearing loss & & yes us no & 93 & 10 & $(10.8 \%)$ & 5 & (5.4\%) & 2.00 & $0.62 \sim 7.46$ \\
\hline
\end{tabular}

Note) significance : "p<0.001." $p<0.01,{ }^{c} p<0.05$

Ca : case, Con: contral

OR: odds ratio, CI : confidence interval

\section{Discussicy}

Previous epidemiological studies indicated that Buerger's disease predominantly affected men and that it rarely occured in women. ${ }^{1-4)}$ The reported proportion of women with Buerger's disease was commonly within the range of $0 \sim 5 W_{0}{ }^{1-4,4,16)}$ In the present series. 6 (3.8\%) out of 159 patients were women. Among them, four patients were smokers and 2 were nonsmokers. Recently the increase in the incidence of women with Buerger's disease has been disclosed, ${ }^{1,1)}$ which paralleled the increase of female smokers in number." Smoking was here again strongly suggested to be a risk factor of Buerger's disease. And the higher incidence of nonsmokers in female patients ${ }^{13}$ suggests the possible involvement of passive smoking in the etiology of Buerger's disease." Our statistical 
Talke 6. Dose-response relation besween smokint index and Buerger's disease, (Analysis of total cases)

\begin{tabular}{|c|c|c|c|c|c|c|}
\hline B.I. & Cose & Control & Totel & Cum. Freq. & $\overline{\mathbf{R} . \mathbf{R} .}$ & Significance \\
\hline$<0$ & $2(1.3)$ & $27(17.8)$ & 29 & 0.0493 & 1.0000 & - \\
\hline$\langle 1 \quad-400\rangle$ & $58(38.2)$ & $57(37.5)$ & IIs & 0.2862 & 13.7368 & $p<0.001$ \\
\hline$\langle 401-800\rangle$ & $59(38.8)$ & $47(30.9)$ & 106 & 0.6497 & 16.9468 & $p<0,001$ \\
\hline$<801-$ & $33(21.7)$ & $21(13.8)$ & 54 & 0.9128 & 21.2143 & $p<0.001$ \\
\hline Total & $152(100.0)$ & $152(100.0)$ & 304 & - & - & - \\
\hline
\end{tabular}

Note) B.I. : Brinkman index, Cum. Freg. : cummulative frequency, R.R. : relative risk Figures in parentheses show percentages.

Table 7. Dose-response relation between smoking index and Buerger's disease. (Analysis of cases whose estimated onset ages were under 50 years old)

\begin{tabular}{|c|c|c|c|c|c|c|}
\hline B.l. & Case & Control & Total & Cum. Freq. & R.R. & Signiffeance \\
\hline$\langle 0\rangle$ & $2(1.8)$ & $21(19.3)$ & 23 & 0.0550 & 1.0000 & - \\
\hline$\langle 1 \quad-400\rangle$ & $47(43.2)$ & $45(41.3)$ & 92 & 0.3188 & 10.9667 & $p<0.001$ \\
\hline$\langle 401-800\rangle$ & 41 (37.6) & $31 \quad(28.4)$ & 72 & 0.6950 & $|3,887|$ & $p<0,001$ \\
\hline $4801-\quad>$ & $19(17.4)$ & $12(11.0)$ & 31 & 0.9312 & 16.6250 & $p<0.001$ \\
\hline Total & $109(100.0)$ & $109(100.0)$ & 218 & - & - & $\overline{-}$ \\
\hline
\end{tabular}

Talke 8. Dose-sesponse relation between smoking index and Buerger's disease. A Analysis of cases wiah angiography. whose estimated azes were under 50 years old)

\begin{tabular}{|c|c|c|c|c|c|c|}
\hline B.I. & Case & Total & Cum. Freg. & R.R. & Sigajflcance & \\
\hline$<0$ & $2(2.2)$ & $16(17.2)$ & 18 & $0.05] \mathrm{I}$ & 1,0000 & - \\
\hline$\langle 1-400\rangle$ & $37(39.7)$ & $40(43.0)$ & 77 & 0.3065 & 7.4000 & $p<0.0 \mathrm{t}$ \\
\hline$\langle 401-800\rangle$ & $36(38.7)$ & $28(30.1)$ & 64 & 0.6855 & 10.2857 & $p<0.01$ \\
\hline$\langle 801-\rangle$ & $18(19.4)$ & $9(9.7)$ & 27 & 0.9301 & 16.0000 & $p<0.001$ \\
\hline Total & $93(100.0)$ & $93(1000)$ & 186 & - & - & - \\
\hline
\end{tabular}

$\boldsymbol{x}^{1}=10.8362$ by Mantel-extension method $(\mathrm{p}=0.000995)$

Note) B.I. : Bcinkman index. Cum. Freq. : cummulative frequency, R.R. : relative risk Figures in parenıheses show percentages.

analyses were done under 3 conditions separately. The phrase of "under 50 years old at the onset" was derived from the diagnostic criteria for Buerger's disease recommended by the MHW'1' and the majority of the literature supported this condition ${ }^{3+4.7 .6 \mathrm{~d} t .123}$ because atherosclerosis, which is often diagnosed as Buerget's disease, increases in frequency among patients over 50 years old. Angiography is said to refine the diagnosis" although it is not included in the diagnostic criteria.

In our study. Buerger's disease was proved to be statistically associated with several exposure factors. The exposure factors which had signilicant odds ratios even when analyses were done most strictly conditioned with both the onset age and angiography were (1) smoking status, (2) less intake of milk, (3) physical work. (4) noisy working environment, (5) dusty working envitonment, and (6) the past history of allergic rhinitis.

It is well established that smoking is deeply related to the exacerbation and remission of Buerger's disease ${ }^{2,4,4,7}$ ) and that habitual smoking is a strong determinant of a risk to the disease. ${ }^{1,5-5,7-9)}$ Strong link between smoking habits and Buerger's disease was here reconfirmed.

Answers to questionnaires, however, are often considered not to be objective, because they are made by patients themselves. The fact that there were two would-be nonsmokers among cases made it clearer that the assessment of smoking status should be done with more objective indicators. To acquire more reliable information concerning smoking habits, some biologi- 
cal parameters are recommended. ${ }^{1,3,41}$ Among them, cotinine, a derivative of nicotine, has been said to be a better index of smoking evidence. Urinary cotinine of snokers were significantly higher than that of nonsmokers. ${ }^{13}$ The test of biological parameters will be of necessity to know not only whether a patient smoked or not but also whether he or she suffered from passive smoking or not. 2.181

Our finding on milk intake contradicted that of the previous report in which patients drank more milk than controls. ${ }^{13)}$ The biological significance of milk intake remains unclear.

On the other hand, employment status may play a role in the etiology of Buerger's disease. ${ }^{\text {(3) }}$ Allergic rhinitis as a risk factor of Buerger's disease has not yet been reported as far as we know.

Before making a conclusion on risk lactors, the potential cofounding factors that might disguise the statistic results should be evaluated. In addition, the accumulation of data will be necessary. At present, smoking sems to solely gain universal acceptance as a risk factor of Buerger's disease among statistically significant risk factors proven in the present study. To assess whether or not a factor is actually involved in the developement of Buerger's disease is such a tough task that the epidemiological study should be pursued in future and that biological methods should also be introduced to give epidemiological findings the etiological guarantec.

\section{R:EFEREACES}

I. Shionoya S. Buerger's distesset: Pathology. Diagnosis and
Trealment. The University of Nagoya Press, Nagoya, 1990.

2. John WJ. Bucrger's disease (Thrombongiitis Obliterans\}. Rheum Direase Clin North Am. 1990: 16(2) : 463470.

3. Lie JT. Buerger's disease and inflammatory aspects of atherosclerosis. Curr Op Rheum, 1990: 2: 76-80.

4. Walter JQ, Williem DJ. PauJ MB. Buerger's disease. Int J Derm. 1989: 28(10): 638-642.

5. James RO. James L, Rodney SM. Gerald FM. Thromboungitis Obliterans (Buerger's disense) and Smokeless Tobaces. Arth Rheum 1987; 30(9): 1054-1056.

6. Nomura F. Sasezuki T, Koyama T, et al, HLA in Buerger's disease. Expl clin Immun. 1986; 3; 195-200.

7. Shionoya S. Buetrer's disease Current Encyclopedis of Pachology 11B, Nakayama Shoten. 1986; 169-174. lin Japanese)

8. Lie JT. Thromboangiitis Obliterans (Buerger's disease) in Woinan. Medicine, 1986; 6S(6): 65-72.

9. Lie JT. The Rise and Fall and Resurgence of Thromboangitis Obliterans (Buerger's disease). Acto Pashol Jpn. $1989 ; 39(3)$ : 153-158.

10. Ishibaghi H, Shionoya S. Sasaki R, Aoki K. An Epidemiological Survey of Butrger's disease in Woman. Annual Repart of Epidemiolory of Intractable Distuses Research Committee 1987. The Minisiry of Health and Welfare of Japan, 1988; 183-184. (in Japenese)

11. Shionoya S, Nighikimi N. Mizuno S. A Nationwide Epidemiological Study of Buerger's disease. Annual Report of Epidemiology of Intractable Diseases Reseanch Committe 1986. The Ministry of Health and Welfare of Japan, 1987 ; 25-26. (in Japanese)

12. Shionoya S. What Is Buerger's Disease? World J Surg. 1983; 7 : 544551.

13. Aoki K. Shionoya S, Matzubara J. Sasaki R. An Epidemiological Study of Buerger's disease - A casecontrol study —_Epidemiological Report of Etiolosy of Buerger's Disease 1983. The Kirin Miemorial Foundation, 1984: 1-15. (in Japanese) 